http://dx.doi.org/10.5007/2175-7968.2013v2n32p57

\title{
O DICTIONNAIRE SUISSE ROMANDE E A LEXICOGRAFIA DIFERENCIAL
}

\author{
René G. Strehler \\ Universidade de Brasília \\ renesstrehler@terra.com.br
}

Resumo: A noção de lexicografia diferencial está pouco difundida fora da francofonia. $\mathrm{O}$ objetivo do presente trabalho é apresentar as peculiaridades da lexicografia diferencial através do Dictionnaire suisse romande (DSR). Baseado em considerações teóricas de Coseriu, Völker ou Glessgen, nós admitimos que a variação faz parte do sistema. Em lexicografia, cabe verificar como as variações (diatópica, diacrónica...) se articulam em volta de um nível linguístico chamado não marcado. A variante normalizada do francês, o français standard, foi elaborada essencialmente pelos grammairiens do século XVII, como Vaugelas ou Bouhours, por exemplo. Na lexicografia francófona, que verdadeiramente apareceu com os dicionários de Richelet (1680) e Furetière (1690), o français standard continua a referência, mas em muitos dicionários, o français standard, embora supranacional, é explicado em função do uso da França. É nesse contexto que aparece a metodologia da lexicografia diferencial. A noção de diferencial se manifesta na seleção da nomenclatura, pois são apresentados no dicionário apenas os lexemas com uso divergente em comparação com dicionários gerais que fornecem um francês de referência, mas não a norma. Em resumo, o DSR consagra uma norma regional, ou subnorma, correspondendo às peculiaridades do francês suíço. Outras obras diferenciais corroboram essa observação: o francês se compõe de um français standard e de normas regionais descritas pela lexicografia diferencial - situação diferente daquela do português, para o qual existe uma norma culta brasileira e uma norma culta de Portugal.

Palavras-chave: Lexicografia diferencial. Variação. Norma 


\title{
THE DICTIONNAIRE SUISSE ROMANDE AND DIFFERENTIAL LEXICOGRAPHY
}

\begin{abstract}
Differential lexicography is little known outside the French-speaking world. This paper seeks to describe the traits of differential lexicography by examining the Dictionnaire Suisse romande (DSR). In line with considerations by Coseriu, Völker and Glessgen, variation is taken here to be an integral part of the system. In lexicography it is a matter of analysing how (diatopic, diachronic, ...) variations are associated with a linguistic level termed "unmarked". The normalised variant of French, so-called standard French, was essentially elaborated by $17^{\text {th }}$-century grammarians such as Vaugelas and Bouhours. In Francophone lexicography, firmly established by the Richelet (1680) and Furetière (1690) dictionaries, standard French continues to be the frame of reference. In many dictionaries, however, standard French is explained in terms of usage in France, despite its supranational status. This is the context in which the methodology of differential lexicography emerges. The notion of what is differential is manifest in the choice of nomenclature. Only lexemes whose usage differs from that described in general dictionaries of French as a frame of reference (but not as a norm) are registered. In brief, the DSR covers a regional norm, or sub-norm, relating to the peculiarities of Swiss French. Other differential works of reference corroborate this observation: French is seen to consist of a standard form and regional norms described by differential lexicography. This contrasts with the situation that holds for the Portuguese language, for which there is an "educated peninsular Portuguese norm" and an "educated Brazilian norm".
\end{abstract}

Keywords: Differential lexicography. Variation. Norm.

\section{Introdução}

A noção de lexicografia diferencial está pouco difundida fora da francofonia. O objetivo do presente trabalho é apresentar as peculiaridades da lexicografia diferencial através do DictionnaireSuisseRomande (DSR) de THIBAULT e KNECHT (1997).

Baseado em considerações teóricas de Coseriu, Völker ou Glessgen, nós admitimos que a variação faz parte do sistema. Em lexi- 
cografia, cabe verificar como as variações (diatópica, diacrónica...) se articulam em volta de um nível linguístico chamado não marcado.

A variante normalizada do francês, of français standard, foi elaborada essencialmente pelos grammairiens do século XVII, como Vaugelas ou Bouhours. No contexto sociocultural da época, e até há pouco tempo, essa norma não foi contestada. Assim, a elite cultural da Suíça romanda seguia o uso de Paris, apesar da ausência de qualquer dependência política.

Na lexicografia francófona, o français standard continua a referência, pois ele é, segundo Corbeil, "lenoyaudur de la langue françaisecommuneà touslesfrancophones" (de VILLERS, 2003, pXVII). Na realidade, em muitos dicionários, o français standard, embora supranacional, é explicado em função do uso da França. Esse fato se averigua igualmente no Trésor de la langue française(TLF, cf 'sites' nas referências), 16 volumes publicados entre 1971 e 1994 pelos linguistas P. Imbs e B. Quémada.

É um fato comum para línguas faladas em vários países, uma descrição do léxico centrada no uso de um único país não é satisfatória para a situação sociocultural de todos os falantes e o exemplo do lexicógrafo NoahWebster (1758 - 1848) mostra como um dicionário pode normalizar a variante de um idioma, nesse caso o inglês americano. Para o francês, o distanciamento da norma de Paris foi percebido, durante muito tempo, como um problema pelos falantes e quando essa percepção mudou, já existia a descrição monumental do TLF.

É nesse contexto que aparece a metodologia da lexicografia diferencial: elaborar um corpus de extração apenas a partir de textos literários, administrativos e jornalísticos oriundos do país cuja variante linguística se descreve; aqui, a Suíça romanda. A noção de diferencial se manifesta na seleção da nomenclatura, pois são apresentados no dicionário apenas os lexemas com uso divergente em comparação com o TLF. Portanto, esse dicionário fornece um francês de referência, mas não a norma, pois as obras 'diferenciais' apresentam a norma linguística a partir do uso observado na região descrita, sem considerar forçosamente o uso da França. 
Em resumo, o DSR consagra uma norma regional correspondendo às peculiaridades do francês suíço. Outras obras diferenciais corroboram essa observação: o francês se compõe de um français standard e de normas regionais descritas pela lexicografia diferencial - situação diferente daquela do português, para o qual existe uma norma culta brasileira e uma norma culta de Portugal.

A continuação será exposto o contexto cultural no qual a lexicografia diferencial apareceu e apresentada uma reflexão em volta de conceitos como 'norma' ou 'francês de referência', para chegar a uma ilustração do DSR.

\section{Contexto cultural}

O entendimento da lexicografia diferencial, tal como ela é praticada na francofonia, exige certos conhecimentos a propósito da história, e não apenas da história cultural, dos povos que falam o idioma em questão. Uma conceptualização resumida da francofonia faz a distinção entre áreas onde o francês é língua segunda (Magreb, África subsaariana, etc.) e áreas onde o francês é língua materna. Essa última área se divide num conjunto europeu e num conjunto norte-americano. Para esse último, cabe mencionar que ele é o resultado do que se chama comumente o 'primeiro ciclo colonial francês', que se caracteriza pelo deslocamento de franceses, ou seja, havia, em alguns momentos, uma política de povoamento. Outro traço importante desse primeiro ciclo é o do império conquistado no século XVII foi perdido no século XVIII, salvo exceções, como as Antilhas. Em outras palavras, além da separação geográfica, a população francófona norte-americana foi separada do então centro cultural, precisamente em um momento em que na França, e essencialmente em Paris, se elaborava e normalizava a variedade do francês que se tornava o 'français standard'. Nesse contexto, todas as condições estavam presentes para o idioma dos quebequenses, por exemplo, se distanciar do francês de Paris, 
mas culturalmente prevalecia a preocupação de não se distanciar do francês que tinha a reputação de ser o bom, a variante da corte de Paris. Ainda nos anos 80 do século passado, dicionários quebequenses que descreveram o francês numa perspectiva norte-americana foram duramente criticados pelos quebequenses eles-mesmos.

Depois de ter constatado a expansão externa, convêm constatar que o francês é igualmente, em termos de P. Bec (1970, tome II, p. 6), uma língua de extensão interna. De fato, numa ótica diacrônica, o francês, o idioma de Paris, é apenas um dialeto entre outros e todos os dialetos da França, da Suíça romanda e da Bélgica são dialetos primários; isto é, provindo diretamente do latim. O francês é o idioma que foi normalizado e que ocupava e ocupa uma posição de prestígio. Essa posição, que implica também que o francês é a língua do rei da França, era suficiente para que essa língua se respaldasse em todo o território do reinado. A Suíça romanda nunca dependeu da França, certos cantões eram cidades-estados, como a Repúblicas de Genebra, de onde vem Rousseau, ou, antes da criação do Estado federal moderno, sob a dependência de cantões alemânicos. Assim como a elite provinciana da França, os suíços adotaram a norma de Paris. A expansão da escola pública obrigatória, no século XIX, fez com que no norte da França, assim como na Suíça romanda, os outros falares românicos desapareceram quase completamente.

Diante dessa situação há evidentemente fatores fortes para provocar a diversificação do léxico do francês. Em termos linguísticos, essa diversificação se manifesta nos dois eixos substrato superstrato e arcaísmo - inovação. Aparece agora a questão de como esses regionalismos são aceitos ou percebidos na sociedade. $\mathrm{Na}$ lexicografia convêm distinguir as obras que visam tratar as peculiaridades regionais, de um lado, das obras que abordam o francês standard, de outro. No primeiro tipo de obras prevalece a visão normativa, que tem o intuito de substituir uma forma julgada incorreta por uma equivalente do francês normativo; títulos como Chasseauxbelgicismes (HANSE; DOPPAGNE; BOURGEOIS- 
-GIELEN, 1971) são, a esse propósito, bastante reveladores do estado de espírito dos autores, mas devemos igualmente notar que, de certo modo, essas obras seguem uma velha tradição; afinal, quando, o latim clássico ainda era a variante de prestígio, o Apendixprobi, que data provavelmente do fim do século II, já visava corrigir o uso das variantes erradas: "COLUMNA non COLOMNA; NUMQUAM non NUMQUA”. Os tempos mudaram e hoje em dia observa-se quesubnormas são assumidas na francofonia, o que se reflete na qualidade científica e metodológica das descrições presentes na Base de donnéeslexicographiquespanfracophone (BDLP), que é a continuação do projeto 'Trésordesvocabulairesfrançais', lançado nos anos 1980 por B. Quemada. No entanto, antes da BDLP, deve-se considerar o Dictionnairehistoriqueduparlerneuchâtelois et suisseromand (PIERREHUMBERT, 1926) como obra precursora na área da descrição científica dos regionalismos franceses. Em resumo, na lexicografia que trata peculiaridades regionais prevalecia, até há pouco tempo, uma visão normativa e corretiva pouco compatível com a lexicografia científica.

$\mathrm{Na}$ lexicografia monolíngue geral, aquela que produz dicionários de língua, a existência e a avaliação dos regionalismos é delicada por causa de vários fatores de difícil manejo numa perspectiva diacrônica, como a visão normativa ou descritiva, ou a origem geográfica do dicionário, entre outros. Com efeito, a origem geográfica de uma obra pode ser pertinente, hoje em dia, quando se pensa em dicionários quedescreveme representamo inglês dos Estados-Unidos ou o inglês britânico. Já no caso do francês, nota-se que o primeiro dicionário (RICHELET, 1680) e o segundo (FURETIÈ$\mathrm{RE}, 1690$ ) inteiramente em língua francesa foram publicados em Genebra e Rotterdam respectivamente, portanto fora da França. Nos chamados Dictionnaires de Trévoux (primeira edição 1704), o apelido 'de Trévoux' se refere ao lugar onde eles foram editados; ou seja, perto de Lyon, portanto numa região que, na época, não fazia parte da França. A primeira obra publicada na França, em Paris, é a primeira edição do Dictionnaire de l'Académiefrançaise, 
que data de 1694. Em relação às obras citadas, a origem geográfica tem pouca importância quanto às perspectivas lexicográficas, porque, na França, apenas a 'Académie' teve o privilégio de publicar dicionários. Além disso, esses dicionários elaboraram a distinção, até hoje usual, entre 'dicionário de língua' e 'dicionário enciclopédico'; mas para a norma dicionarística, há um certo consenso: trata-se nestas obras o francês hoje chamado standard. A primeira edição do dicionário da Academia não considerava, ao menos a um nível teórico, como francês arcaísmos ou neologismos, nem os termos das ciências ou os regionalismos. Na continuação a Academia passava a uma visão mais moderada, mas o fato pertinente para a lexicografia francesa geral é que não se descreve claramente o francês de uma delimitação geográfica, mas o 'francês standard', que tem certa vocação supranacional. Esse funcionamento se observa ainda hoje em dicionários como o Grand Robert(GR, cf. nas referências REY, 2005), o Petit Robert (PR, cf.nas referências REY-DEBOVE, 2007), o Multidictinnaire ou o monumental Trésor de la langue française que trata o francês standard essencialmente baseado no uso da França. Nesse contexto, os regionalismos não estão ausentes nessas obras, mas sua definição se faz a partir do standard adotado. Em termos práticos, isso significa definições insuficientes para o falante que incorpora um desses regionalismos na sua subnorma regional, ou percepção divergente entre francês standard e francês regional a propósito das condições de emprego; mas há igualmente bastantes verbetes que apenas ancoram uma unidade lexical numa dada região. Em todos os casos nota-se a ausência de condenações tão taxativas como aquelas que se encontram em muitas obras se limitando em inventariar os regionalismos. Seguem alguns exemplos de 'regionalismos' para ilustrar concretamente o funcionamento dos dicionários citados:

\section{- fayard, fayart ou foyard('faia')}

Os dicionários Trévoux, TLF, GR e PR fixaram, com maior ou menor precisão, a unidade lexical no espaço geográfico; 
nos dicionários mais recentes recorre-se a marcas de uso, como "Région (Centre, Est, Suisse)" no PR. O Trévoux indica a extensão geográfica no interior da definição: "dansleLyonnais". O Littré, que trata a variante 'Fayard', indica que o lexema é um nome vulgar da faya('hêtre' em francês standard), sem indicar qualquer extensão geográfica. $\mathrm{O}$ DSR, seguindo sua lógica diferencial, não comporta marca geográfica a propósito de 'fayard' ou 'foyard' .

- mômier, momier ('santarrão, tartufo'; 'dissidente de uma igreja protestante')

O Littré trata as duas acepções com a indicação "enSuisse" e informa que o sentido de 'santarrão' é "par dénigrement". Para o TLF 'santarrão' fica sem marca e a acepção referente à dissidência religiosa se vê localizada com "enSuisse". O DSR trata todas as acepções, inclusive aquelas ausentes nas outras obras, como pejorativas.

- nonante ('noventa')

Os dicionários da Academia (1762), Furetière e Richelet informam que o discurso ordinário prefere 'quatre-vingt-dix', o dicionário da Academia indica ainda que o termo serve na aritmética/matemática. Littré até acrescenta "nonante envelhece e isso é uma pena, continua de uso frequente na Suíça, na Savoia e no sul da França". No DSR 'nonante' não recebe nenhuma marca de uso, mas ele menciona ainda a variante 'noinante' que, ela, é avaliada como arcaismo e como regionalismo no interior da Suíça romanda.

- septante ('setenta')

Salvo a propósito da tradução da Bíblia, 'septante' é considerado como arcaísmo pelos dicionários franceses; já o dicionário de Nicot (1606) afirma "Septante ou soixante\&dix". Littré acha 'septante' preferível ao termo padrão, mas nota que 'septante' está em uso apenas no sul da França. O TLF e o GR precisam a extensão geográfica onde o lexema não envelheceu. Para o DSR 'septante' corresponde a um em- 
prego valorisado, mas ele menciona também que o lexema, na história, já foi condenado e valorizado ao mesmo tempo.

Esses poucos verbetes já mostram que a descrição dos chamados regionalismos não é uniforme; ou seja, os dicionários da França não conseguem elaborar uma descrição precisa do francês regional, fato que aparece nas divergências quanto à extensão geográfica dos lexemas, mas igualmente nos julgamentos diafásicos às vezes inadequados diante do uso real numa dada região, sem falar nas acepções não tratadas, como em 'mômier'. Porém, deve-se igualmente mencionar que essas obras se abstêm geralmente de julgamentos fortes condenando um regionalismo pelo simples fato de ser um regionalismo.

Uma descrição do 'francês regional' se averigua, nesse contexto, útil. Ela permite ao falante de uma dada região encontrar uma explicação mais em acordo com sua realidade linguística. Todavia, essa descrição precisa de bases metodológicas adequadas para garantir a qualidade e a utilidade da descrição. Segue a exposição em grandes linhas da metodologia adotada na lexicografia diferencial do francês.

\section{A norma, o 'français standard' e o 'français de ré- férence'}

Para entender o caráter diferencial da lexicografia aqui em questão, cabe expor brevemente o Trésor de la langue française (CNRS, França), pois essa obra é o maior dicionário da língua francesa e, sem dúvida, um dos mais voluminosos do mundo. A obra foi publicada em 16 volumes entre 1971 e 1991 e, hoje em dia, é gratuitamente consultável na internet (http://atilf.atilf.fr/). Considera-se o TLF como uma obra pioneira na lexicografia informatizada. Os dois primeiros organizadores foram Paul Imbs e Bernard Quemada. Esse último, como já foi dito, fomentou igualmente 
os trabalhos em torno do projeto 'Trésordesvocabulairesfrançais'. $\mathrm{O}$ corpus que serviu à elaboração do TLF era inteiramente informatizado, fato excepcional na época; ele foi constituído essencialmente a partir da literatura francesa do século XIX e da primeira metade do século XX. A norma dicionarística foi estabelecida a partir da noção de 'français standard'; mas, se o francês standard é supranacional, o nível não marcado se baseia, a nosso ver, no uso observado na França, fato já constatado nos poucos exemplos citados precedentemente.

Sendo assim, aparece de novo a questão de saber como chegar a uma descrição do léxico de uma região delimitada. Contrariamente às línguas inglesa ou portuguesa, por exemplo, a língua francesa continua com o maior número de falantes no seu país de origem. Apenas para comparação, lembramos que o Brasil tem 192 milhões de habitantes e Portugal apenas 10; os Estados-Unidos têm 317 milhões de habitantes, a Grã-Bretanha apenas 58; mas a França tem 65 milhões de habitantes e a província do Québec apenas 8 (dados:wikipedia 2012). Diante do trabalho lexicográfico já existente para o 'français standard' e da situação demográfica, torna-se difícil realizar um projeto lexicográfico comparável com aquele do TLF para um país ou uma região específica da francofonia. O custo econômico seria demasiadamente elevado, sem falar que o resultado seria em muitos aspectos comparável com aquele do TLF, pois o francês standard é uma realidade supranacional aceita e esse francês, tal como aparece no TLF ou no GR pode ser aproveitado numa metodologia adequada,

Para o DRS, falar em metodologia adequada significa que o corpus constituído para sua elaboração contem exclusivamente textos jornalísticos, administrativos, literários, e outros, de origem suíça francófona. A noção de 'diferencial' implica mediar o distanciamento de um lexema empregado na Suíça com seu uso em francês standard e para fazer isso, o TLF, como outros dicionários franceses, podem servir de corpus d'exclusão. Nessas circunstâncias intervém uma reinterpretação do francês presente no TLF e outras 
obras como o GR, por exemplo. Esses dicionários se baseiam, para sua descrição do léxico, numa norma que fornece o nível estilisticamente não marcado, mas ele trata igualmente lexemas que fogem dessa norma em função das possibilidades variacionistas. Diante desse fato, o DSR não pode servir-se do francês do TLF como norma, mas como francês de referência; ou seja, o TLF ou o GR fornecem o francês que permite mediar o distanciamento semântico de um lexema em uso na Suíça. Caso não há divergência num lexema entre o uso helvético e o uso observado no TLF, a palavra em questão não integra a nomenclatura do DSR. Se há divergência, o trabalho lexicográfico consiste em interpretar essa diferença à luz do uso linguístico corriqueiro na Suíça e não basear-se na avaliação do TLF. Em outras palavras, um arcaísmo na perspectiva francesa não é forçosamente um arcaísmo na Suíça, um regionalismo de um dicionário francês não é forçosamente um regionalismo no DSR. O resultado desse procedimento, já aplicado no Trésor de la langue françaiseau Québec(integrado no site http://www.bdlp.org ) ou no DSR, por exemplo, é uma situação linguístico-normativa diferente daquela observável na lusofonia. De fato, para o português, autores como Bechara $(2004,34)$ mencionam o português do Brasil e o português de Portugal como duas normas de correção. Para a francofonia, a um nível supranacional o francês standard continua fornecendo a norma supranacional geralmente aceita nos vários países e regiões da francofonia. Ao lado dessa norma supranacional, a lexicografia diferencial consagra subnormas vigentes nas diferentes regiões descritas. Assim o DSR consagra certas feminizações na época ainda inusitadas no francês da França, como "auteur(e)n.f.", "ingénieuren.f." ou "ministren.f.". Para 'ingénieure' o DSR observa que se trata de uma aparição recente na Suíça romanda, provavelmente tirado do uso quebequense; no caso de 'ministre'na versão papel (1997) há a observação "En France, onditMadame le ministre" enquanto na versão on-line de 2008 leia-se "En France, on a longtempsditMadame le ministre". Essas poucas observações mostram que o DSR assume uma subnorma, 
ou norma regional suíça, e isso dialogando com a norma e os usos da França, como mostra o acrescimento de 'longtemps' a propósito do feminino de 'ministre'.

Depois dessas observações a propósito de metodologias que ilustraram como a lexicografia reinterpreta conceitos como 'norma' e 'standard' em função da área linguística descrita, cabe ver o que é concretamente o DSR.

\section{Ilustração do DSR}

O DSR (THIBAULT; KNECHT, 1997) é um dicionário com uma macroestrutura e microestrutura típica para a chamada lexicografia diferencial e, sendo assim, os verbetes do DSR são bastante parecidos com aqueles do Dictionnairedesrégionalismes de France (REZEAU, 2001), por exemplo. Não se trata em apenas definir um dado lexema, trata-se em expor os empregos pelo intermediário de exemplos literários e outros e de comentar a etimologia, história ou extensão geográfica do lexema, entre outras informações. Nessa situação, o consulente que apenas quer conhecer o significado de um lexema arrisca de se perder nesses verbetes, pois ainda prevalece o discurso que comprova um fato linguístico e não aquele que apenas explica e ilustra esse fato. Nesse sentido podemos considerar os dicionários diferenciais como obras lexicográficas científicas, em face de dicionários de língua geral que são obras lexicográficas de consulta; com isso não queremos dizer que não haveria ciência em dicionários como o GR, mas que os dicionários de língua geral já não precisam mais justificar cientificamente a presença de tal ou tal lexema.

O DSR dispõe de uma parte pré-dicionarística bastante desenvolvida que explica os aspectos históricos, culturais e metodológicos que conduzem a elaboração da obra; essa parte apresenta igualmente o 'corpus das citações'. Na parte pós-dicionarística encontram-se vários índices, como as palavras da Suíça romanda 
que se encontram igualmente em outras regiões da francofonia, ou a lista de equivalentesem alemão suíço e italiano suíço de certos romandismos. Além de um índex por campos conceptuais (vestuário, bebidas, etc.) há igualmente um índex inverso que facilita certas comparações morfológicas, pois a lista permite encontrar todos os lexemas em -ée ou em -eur, por exemplo.

Sem dúvida, a parte mais interessante para ilustrar a lexicografia diferencial é a partedicionarística; ou, mais precisamente, os verbetes. Para ilustrar o modelo da microestrutura empregada no DSR, apresentamos o verbete "arcade", sem proceder a nenhum corte:

ARCADE n. f.

- Local commercial, de surface réduite, servant à abriter des commerces divers tels boutiques de vêtements, kiosques à journaux, salons de coiffure, pharmacies, pâtisseries, boulangeries, cordonneries, etc. Arcade à louer; arcade commerciale; arcade divisible ; arcade sur deux niveaux, de plain-pied.

"A Louer / dans immeuble neuf, à la route des Acacias / avec parking / 1 ou 2 arcades de $120 \mathrm{~m}^{2}$ environ avec sous-sol.» Feuille d'Avis officielle du canton de Genève, 10 janvier 1973, p. 23.

« A Genève / grande arcade / boutique prêt-à-porter féminin connue près du centre, sur très bon passage [...], bel agencement*, 4 cabines essayage, [...].» Nouvelliste et Feuille d'Avis du Valais, 19 novembre 1976, p. 22.

« $A R C A D E$ à remettre*, vieille ville, bon passage, prêtà-porter masculin, féminin. $60 \mathrm{~m}^{2}$ environ sur 2 niveaux.» La Suisse, 29 mars 1977, p. 22.

"Lundi matin vers 10 heures, la voirie finissait de 
balayer les morceaux de verre qui jonchaient la place. Dansl'arcade calcinée, on distinguait quelques ananas, des oranges, des boîtes de foie gras défoncées, [...]. Elle [la maison Fauchon] a également une pâtisserie-confiserie, avec bar, située à quelques pas de l'épicerie. Cette seconde arcade n'a été que superficiellement touchée par la déflagration.» Tribune de Genève, 20 décembre 1977.

«A louer / plein centre de Genève / arcade d'angle / rue du Rhône / environ $200 \mathrm{~m}^{2}$, sur 2 niveaux, donnant sur une des rues les plus commerçantes de Genève.» Tribune de Genève, 15 novembre 1979, p. 14. "A remettre* / Acacias-Carouge / arcade agencée* $75 \mathrm{~m}^{2}$.» Tribune de Genève, 5 mars 1982, p. 61.

« A LOUER DANS / CENTRE COMMERCIAL DE SION/ - une arcade de $75 \mathrm{~m}^{2}$ / libre dès le 1.7.1993» Nouvelliste et Feuille d'Avis du Valais, 24 mai 1993, p. 13.

Local. Essentiellement attesté à Genève ; attestations sporadiques dans des journaux vaudois, valaisans, jurassiens, etc.

Rem. Dans les autres cantons, on dit plutôt local commercial. - Les arcades disposent souvent d'un dépôt au sous-sol. Dans les petites annonces, les immeubles commerciaux sont en général décrits comme comportant des arcades et des bureaux.

Métonymie à partir du sens du français général $a r$ cades pl. «galerie ouverte servant de passage et bordant les rues de certaines villes» (TLF 3, 406b s.v. arcade A 3). Ces galeries ouvertes sont normalement bordées de boutiques, cf. par exemple les arcades de 
la rue de Rivoli, à Paris. - TLF 3, 406b s.v. arcade A 3 ; SchuleListeLar 1978 ; Had 1983; FEW 25, 130b, ARCUS I 2; PLidp. 1989.(DSR, 1997, p. 83)

O primeiro campo do verbete, evidentemente, é a entrada, que vem sistematicamente acompanhada da classificação gramatical ("n.f." no caso do exemplo), salvo quando se trata de uma entrada-remissiva, como "METTRE À BAN $\rightarrow$ BAN1" onde o consulente se vê convidado a consultar a primeira locução do verbete "BAN". Em certos casos, a entrada pode ser acompanhada de uma transcrição fonética e/ou de uma grafia alternativa: "FGEHN [f̊:n] n.m. (exc. FÖHN)".

A definição é introduzida pelo losango cheio, $\downarrow$, e frequentemente acompanhada de exemplos de emprego em itálico. No caso de "arcade" cabe ainda mencionar que o DSR recorre a um gênero próximo (local comercial) e diferenças específicas (de superfície reduzida, etc.) sem recorrer ao artifício de prender o definido numa região específica. Esse último recurso se observa com certa frequência em dicionários gerais, como o TLF ou o GR, quando são tratados certos regionalismos, mas, as duas obras não tratam a acepção aqui em questão.

Na estratégia do DSR, as abonações não se confundem com os exemplos de emprego, em geral forjados. As abonações servem para comprovar o emprego do termo da entrada. É essa função que explica o número relativamente elevado de abonações. No verbete "arcade", há sete abonações provindas de jornais e de textos administrativos ou assimiláveis, pois a "Feuille d'Avis officielle" é o equivalente do Jornal oficial da União ou de uma região. Certo número de palavras desses textos é seguido de um asterisco (agencement*, remettre*), esse recurso indica ao consulente que a palavra assim tratada faz igualmente parte da nomenclatura, em ordem alfabética, do DSR. 
Dando continuação à exploração do verbete, passamos ao campo seguinte. "Local.", abreviação de 'localização', introduz um campo facultativo que trata da extensão geográfica da palavra em questão. As indicações podem ser nuançadas como no presente exemplo, em outros casos pode haver apenas as abreviações dos cantões suíços, GE para 'Genève' ou VD para Vaud, por exemplo. As palavras ou acepções empregadas em todo o território da Suíça romanda não recebem nenhuma observação no campo 'localização'.

"Rem.", remarques (observações), é um campo não obrigatório, mas presente de maneira quase sistemática. Ele serve para precisar as condições de uso de um dado lexema. No caso do exemplo, o DSR indica a variante mais usual na Suíça; mas encontram-se igualmente indicações que um dicionário como o GR trataria com uma marca de uso diacrônica, por exemplo. Em outros exemplos, o DSR se serve dessa rubrica para apresentar não o seu julgamento a propósito de um lexema, mas o julgamento que parece estar em vigor na comunidade linguística. Assim leia-se no campo "Rem." do verbete "servir" e a propósito do particípio passado "Frequente na oralidade, mas raríssimo na escrita, o emprego sendo percebido como errado. Criticado por alguns [...]".

$\mathrm{O}$ retângulo, $\square$, introduz o último campo do verbete. Encontram-se nessaparte observações que dizem respeito à etimologia da palavra, mas igualmente comentários históricos ou indicações de outros dicionários pertinentes para a apreensão do lexema tratado. Ao lado das numerosas abonações, esse campo é sem dúvida o segundo que mais distancia a lexicografia diferencial da lexicografia geral, pois as referências aqui presentes (TLF $=$ Trésor de la langue française; FEW = FranzösischesEtymologischesWörterbuch) inserem o discurso do DSR num discurso linguístico, lexicográfico ou histórico mais amplo.

Com o verbete "dévaloir" estamos diante de um lexema tratado igualmente pelo GR e, como subentrada em "dévaler", pelo TLF. Representamos o verbete com cortes para apresentar apenas os aspectos pertinentes para a ilustração do DSR: 


\section{DÉVALOIR n. m.}

1. Couloir dans les forêts de montagne, naturel ou aménagé, utilisé pour faire descendre les billes de bois. L'entrée du dévaloir. Au pied d'un dévaloir. Dévaloir de billons. $=>$ châble.

« Tel est ce bisse* du Levron, [...] car qui donc osait s'aventurer dans ces affreux dévaloirs, le long de ces parois vertigineuses [...]» Cl.Bérard, Bataille pour Veau, 1976, p.92 (1 éd. 1963).

\section{$[\ldots]$}

V. encore s.v. verne 1.

$\diamond$ (emplois fig.)

"La rue de la Prairie s'incline doucement vers le sud, dévaloir gris au bout duquel les maisons sont alignées comme les éléments d'une maquette.» J. Vuilleumier, L'Écorchement, 1972, p. 99.

\section{$[\ldots]$}

Rem. [...] Ce verbe a donné lieu au dér.dévalage $n$. $\mathrm{m}$. «descente des billes de bois dans les dévaloirs» (v. Pier s.v.châblage pour une attestation de 1900) ; des témoins de Moutier (BE) l'attestent encore dans la signalisation routière (panneaux Attention! Dévalage de bois!) ; v. encore GrafBern 1987 s.v.châblage. 
2. Vide-ordures, dans un immeuble. Jeter ses déchets dans le dévaloir.

" [...] que chaque corps de bâtiment disposait d'un dévaloir de grand format [...].» M.-G.Prêtre, $\mathrm{La} \mathrm{Cu}$ lotte des anges, 1964, p. 41.

\section{$[\ldots]$}

Rem. Vieilli ; ce dispositif n'existe plus (il a été interdit pour des raisons d'hygiène).

口 Dér. de dévaler (v. rem. ci-dessus), suff. -oir (<-ATORIU). Création suisse romande. [...](DSR, 1997, p. 320-321)

"Dévaloir" ilustra o caso do verbete com mais de uma acepção. O DSR introduz os significados principais com o losango cheio, acompanhado de um número $(1 \downarrow, 2 \downarrow)$. Já o losango vazio $(\diamond)$ no interior da primeira acepção precede um sentido particular, emprego figurativo no exemplo. Cada acepção recebe um tratamento lexicográfico parecido com o que foi visto em "arcade". Para "dévaloir1" notamos que a definição pode ser acompanhada de uma remissiva (=>châble). Os dois campos "Rem." permitem entender o valor do lexema com maior precisão que permitiria a consulta do GR. De fato, esse último define as duas acepções de maneira parecida que o DSR, mas, para a primeira acepção ele não estabelece a ligação com "dévalage" ou "châblage" e, para a segunda, não se nota que a acepção está envelhecida por razões extralinguísticas, pois o dispositivo foi proibido por questões de higiene. Baseado no último campo do verbete, pode-se notar que "dévaloir" é uma criação suíça, enquanto "arcade" se caracteriza por uma especialização semântica. 
No caso de "tune" estamos diante de um lexema conhecido na França e na Suíça. O verbete abreviado do DSR é o seguinte:

\section{THUNE n. f.}

- (fam.) Pièce de cinq francs suisses. Mettre une thune dans l'automate*. = > Borromini; vreneli.

$[\ldots]$

$\square$ Le mot thune au sens de «pièce de cinq francs» est attesté en France dp. 1828-29 (v. TLF) mais ce sens est donné comme marqué dans les dictionnaires les plus récents («pop.» Rob 1964; «arg. » Lar 1964; «par ext. et pop., vieilli» GLLF 1978; «pop., vieilli» GR 1985; «arg., pop., vieilli» TLF). Le mot est cependant encore courant en France, mais pour désigner l'argent d'une manière générale, et plus nécessairement une pièce de monnaie en particulier (déjà Colette, 1954, v . TLF; « un des quelque six ou sept mots qui désignent aujourd'hui l'argent» MerleArgot 1996; v. encore GoudaillierFrançCités 1997). En Suisse romande, en revanche, thune continue de s'employer avec le sens spécifique de «pièce de cinq francs» (bien que le sens français y soit aussi connu sporadiquement, v. Manno 1994, p. 212). - Matériaux et marques à aj. à FEW $19,189 \mathrm{~b}$, TUNIS 2 c. - L'équivalent en Suisse allemande estFunfliber n. m. (v. Duden- Schweiz 1989). - Had 1983; Nie 1987; StRobert 1993.(DSR, 1997, p. 694-695)

Nesse verbete o trabalho do lexicógrafo parece ser, antes de tudo, fazer entender a diferença de valor do lexema em comparação com o 
emprego na França. Contrariamente ao uso observado na França, o lexema não envelheceu na Suíça e ele guarda seu significado primeiro, que é 'cinco francos'. O DSR mostra, igualmente, que a percepção diastrática do lexema não é a mesma nos dois lados da fronteira, pois o DSR o considera apenas 'familiar', enquanto a lexicografia francesa recorre a marcas como 'popular' ou 'gíria'.

Os três exemplos precedentes mostram como uma língua pode emprestar caminhos diferentes, segundo a região contemplada, falta ainda um exemplo que mostra que, segundo a região de uma 'fonia', os empréstimos também podem variar. O lexema "trax" (buldôzer), emprestado ao alemão da Suíça é um exemplo disso; no entanto, em termos de tratamento lexicográfico o verbete não traz novidade em relação ao que já foi visto.

\section{Considerações finais}

No contexto francófono, a história cultural e política explica porque existe uma única língua padrão, o francês standard, que tem a reputação de ser supranacional; enquanto, para o português, por exemplo, é questão de uma norma culta brasileira e de uma norma culta portuguesa. Mas, como o francês é uma língua com uma extensão territorial imensa, como o português, não surpreende que a norma única não corresponde à realidade sociolinguística concreta.

Se para o português existe uma lexicografia geral descrevendo o português do Brasil, com a sua norma específica, e uma lexicografia geral descrevendo o português de Portugal, igualmente com a sua norma específica, para o francês uma outra solução aparecia para conciliar norma e variação. A lexicografia diferencial, de certo modo, é uma extensão da lexicografia geral, já que ela consagra normas regionais, ou subnormas.

A lexicografia diferencial supera uma insuficiência da lexicografia geral, porque ela permite uma descrição precisa de fatos linguísticos que escapam mesmo a obras como o GR ou o TLF. O 
consulente de uma obra como o DSR deve saber que ele encontra nessas obras descrições precisas e extensas dos fatos linguísticos da região tratada, inclusive as avaliações estilísticas adequadas ao uso da região, ou seja, a subnorma está consagrada.

\section{Referências}

BAVOUX. C. (dir.). Le français des dictionnaires. Bruxelles: De Boeck/Duculot, 2008.

BEC, P.Manuel pratique de philologie romane.Paris: A. \& J. Picard : 1970. [2 vol.]

BECHARA, E.Moderna gramática portuguesa. $34^{\mathrm{a}}$ edição revista e aumentada, Rio de Janeiro: Editora Lucerna, 2004.

BÉJOINT, H.; THOIRON, P. (orgs.). Les dictionnaires bilingues. Bruxelles: De Boeck/Duculot, 1996.

BORBA, F. da S.Organização de dicionários. Uma introdução à lexicografia. São Paulo: Editora Unesp, 2003.

BOULANGER, J.-C. Lexicographie générale, notes de cours. Québec: Université Laval/Société Dictionelinc., 1995.

CERQUIGLINI, B.Une langue orpheline.Paris: Minuit, 2007.

COSERIU, E. Los conceptos de 'dialecto', 'nivel' y 'estilo de lengua' y el sentido proprio de ladialectología.Lingüísticaespañolaactual. Madrid: Instituto de CooperaciónIberoamericano, 1981. 
COSERIU, E.Sprachkompetenz: Grundzüge der Theorie des Sprechen. Tübingen: Francke, 1988.

GAUDIN, F. ; GUESPIN, L.Initiation à la lexicologie française. De la néologie aux dictionnaires. Bruxelles: De Boeck/Duculot,2000.

GLESSGEN, Martin-Dietrich \& THIBAULT, André (orgs.). La lexicographie différentielle du français. Strasbourg : Presses Universitaires de Strasbourg, 2005.

GLESSGEN, M.-D. Linguistique romane. Paris: Armand Colin, 2007.

HANSE, J.; DOPPAGNE, A.; BOURGEOIS-GIELEN, H. Chasse aux belgicismes. ?, Fondation Ch. Plisnier, 1971.

KRISTOL, A. Une Francophonie polycentrique : lexicographie différentielle et légitimité des français régionaux.Mélanges offerts à...,no prelo, 2012.

POIRIER, C. La Dynamique du français à travers l'espace francophone à la lumière de la Base de données lexicographiques panfrancophone.Revue de linguistique romane Tome 69, p. 483-516. Strasbourg : Société de Linguistique Romane,2005.

SCHLAEFER, M. Lexicologie und Lexicogrphie. Berlin: Erich Schmidt Verlag, 2009.

STREHLER, R. Observations sur leDictionnaire québécois d'aujourd'hui.International Journal of Lexicography.Vol 10, number 1. Oxford: University Press, 1997.

STREHLER, R.; GOROVITZ, S. Manual do RepLET. Brasília: Thesaurus, 2011.

THIBAULT, A. Lexicographie scientifique et aménagement linguistique : l'expérience du Dictionnaire suisse romande ». In BAVOUX, C.Le français des dictionnaires. Bruxelles : De Boeck/Duculot, 2008.

WARTBURG, W.von. Évolution et structure de la langue française. Berne: Francke, 1949. 
VÖLKER, H. La linguistique variationnelle et la perspective intralinguistique. Revue de linguistique romane. Tome 73, p. 27-76. Strasbourg: Société de Linguistique Romane, 2009.

WELKER, H. A.Dicionários. Uma pequena introdução à lexicografia. Brasília: Thesaurus, 2004.

\section{Dicionários}

IMBS, P. (org.). Trésor de la langue française. Institut national de la langue française (INALF) 1971-1994, 16 vol. (www. http://atilf.atilf.fr)

FURETIÈRE, A. Dictionaireunivesel. La Haye: [s.n], [1690?].

NICOT, J. Thresor de la langue francoyse. Paris: D. Douceur, 1606.

PIERREHUMBERT, W. Dictionnaire historique du parler neuchâtelois et suisse romande. Neuchâtel, ?,1926.

REY, A. (dir.). Le Grand Robert. Paris: ediçõesLeRobert. Reeditado anualmente, versão eletrônica utilizada: 2005.

REY-DEBOVE, J.; REY, A.Le nouveau Petit Robert. Paris: edições LeRobert. Reeditado anualmente, versão eletrônica utilizada: 2007.

REZEAU, P.Dictionnaire des régionalismes de France. Bruxelles: De Boeck/ Duculot, 2001.

RICHELET, P. Dictionnaire françois contenant les mots... Genève: J. H. Widerhold, 1680.

THIBAULT, A.; KNECHT, P.: Dictionnaire suisse romand. Genève: Zoé, 1997. De VILLERS, M.-É.Multidictionnaire de la langue française. Montréal: Éditions Québec Amérique, 2003. 


\section{Sites}

http://www.bdlp.org/Base de données lexicographiques panfrancophone

http://atilf.atilf.fr/TLFi, Le Trésor de la langue française informatisé.

Recebido em 23/12/2012

Aceito em 02/06/2013 